\title{
Treadmill Running Improves Spatial Learning Memory Through Inactivation of Nuclear Factor Kappa B/Mitogen-Activated Protein Kinase Signaling Pathway in Amyloid- $\beta$-Induced
} Alzheimer Disease Rats

\author{
Sang-Hoon $\mathrm{Kim}^{1}$, Young Jun $\mathrm{Ko}^{2}$, Jee-Youn Kim³ ${ }^{3}$ Young-Je Sim${ }^{4}$ \\ ${ }^{1}$ Department of Sport \& Health Sciences, College of Art \& Culture, Sangmyung University, Seoul, Korea \\ ${ }^{2}$ Major in Sport Service Practice, College of Welfare Convergence, Kangnam University, Youngin, Korea \\ ${ }^{3}$ School of Global Sport Studies, Korea University, Sejong, Korea \\ ${ }^{4}$ Department of Physical Education, Kunsan National University, Gunsan, Korea
}

\begin{abstract}
Purpose: Exercise is known to reduce proinflammatory cytokines production and apoptosis. We investigated the effect of treadmill running on spatial learning memory in terms of activation of nuclear factor kappa B (NF- $\mathrm{kB}$ ) and mitogen-activated protein kinase (MAPK) signaling pathway in Alzheimer disease (AD) rats. We also evaluated the effect of treadmill running on proinflammatory cytokine production and apoptosis.

Methods: Using the stereotaxic frame, amyloid- $\beta(\mathrm{A} \beta)$ was injected into the lateral ventricle of the brain. The rats belong to treadmill running groups were forced to run on a motorized treadmill for 30 minutes per a day during 4 weeks, starting 3 days after $\mathrm{A} \beta$ injection. Morris water maze task was done for the determination of spatial learning memory. Terminal deoxynucleotidyl transferase dUTP nick end labeling (TUNEL) assay, immunohistochemistry for cleaved caspase-3, and western blot for

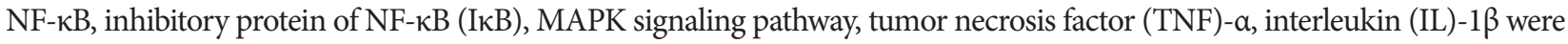
done.

Results: Induction of AD increased proinflammatory cytokine secretion by activating the NF- $\mathrm{KB} / \mathrm{MAPK}$ signaling pathway. These changes induced apoptosis in the hippocampus and reduced spatial learning memory. In contrast, treadmill running inactivated the NF-kB/MAPK signaling pathway and suppressed proinflammatory cytokine production. These changes inhibited apoptosis and improved spatial learning memory.

Conclusions: Current results showed that treadmill running promoted spatial learning memory through suppressing proinflammatory cytokine production and apoptosis via inactivation of NF-kB/MAPK signaling pathway. Treadmill exercise can be considered an effective intervention for symptom relieve of $\mathrm{AD}$.
\end{abstract}

Keywords: Treadmill exercise; Alzheimer disease; Apoptosis; Inflammation; Amyloid- $\beta$

- Fund/Grant Support: This work was supported by the Ministry of Education of the Republic of Korea and the National Research Foundation of Korea (NRF-2018S1A5A2A01032722).

- Research Ethics: This experiment was deliberated by the Animal Care and Use Committee and acquired the approval number (KSNU-2020165).

- Conflict of Interest: No potential conflict of interest relevant to this article was reported.

Corresponding author: Young-Je Sim (iD https://orcid.org/0000-0002-9574-3135 Department of Physical Education, Kunsan National University, 558 Daehak-ro, Gunsan 54150, Korea

Email: simyoungje@gmail.com

Submitted: March 5, 2021 / Accepted after revision: April 27, 2021
This is an Open Access article distributed under the terms of the Creative Commons Attribution Non-Commercial License (http://creativecommons.org/licenses/by-nc/4.0/) which permits unrestricted non-commercial use, distribution, and reproduction in any medium, provided the original work is properly cited. 


\section{- HIGHLIGHTS \\ - Injection of A $\beta$ impaired spatial learning memory and increased proinflammatory cytokines production and apoptosis. \\ - Treadmill running improved spatial learning memory via inactivation of NF-KB/MAPK signaling pathway. \\ - Treadmill running inhibited proinflammatory cytokine production and apoptosis.}

\section{INTRODUCTION}

Alzheimer disease $(\mathrm{AD})$ is a typical brain degenerative disorder that causes neuronal cell death. Although the cause of $\mathrm{AD}$ has not been accurately reported, it has been reported to be associated with oxidative stress due to amyloid-beta $(\mathrm{A} \beta)$ accumulation in the cerebrum, dysfunction of nerve fiber bundles due to over phosphorylation of tau protein, and increased inflammatory substances $[1,2]$. In particular, through various researches, it has been known that inflammation of neurons is closely associated with the onset of $\mathrm{AD}[3,4]$.

Inflammation is a critical reaction for the immune system to pathogen, injured cells, and irritations $[5,6]$. Brain inflammation causes neurodegeneration, including necrosis and apoptosis through tumor necrosis factor- $\alpha$ (TNF- $\alpha$ ) and interleukin 1 beta (IL-1 $\beta$ ) $[6,7]$. A $\beta$ promotes inflammatory response of the brain, of which brain inflammation contributes to the onset of $\mathrm{AD}$ and Parkinson disease [8-10]. $\mathrm{A} \beta$ is a major feature of $\mathrm{AD}$, where overproduction of $A \beta$ leads to the formation of plaque [11].

Mitogen-activated protein kinase (MAPK) cascade is implicated in the cell growth, migration, proliferation, differentiation, and apoptosis. Long-term activation of MAPK is suggested to promote cell death [12]. The activity of nuclear factor kappa $\mathrm{B}(\mathrm{NF}-\mathrm{kB})$ is maintained by the inhibitory protein of NF$\kappa \mathrm{B}(\mathrm{I} \kappa \mathrm{B})$. However, when I $\mathrm{B}$ is phosphorylated by an external stimulus, proteasome-mediated degradation occurs. Active NF$\kappa \mathrm{B}$ induces the expression of inflammatory cytokines, which causes neuronal cell death in the brain [13].

Apoptosis is an important mechanism for maintaining normal cell or tissue homeostasis when inflammation increases, but excessive or inadequate apoptosis caused by external changes or stimuli leads to neurological disease [14]. The activation of various caspases is an important step in the apoptosis process, and caspase- 3 activation plays as an executor of apoptosis [15]. The B-cell lymphoma 2 (Bcl-2) family is distinguished by function into anti-apoptotic proteins and proapoptotic proteins, which can determine the mitochondrial response to apoptosis stimulation. Among the Bcl-2 family, Bcl-2 suppresses apoptosis stage by blocking cytochrome $\mathrm{c}$ release from mitochondria, while the Bcl-2 related X protein (Bax) inhibits apoptosis process [16]. Terminal deoxynucleotidyl transferase-mediated dUTP nick end labeling (TUNEL) staining is an experimental method to find DNA fragmentation, a typical feature indicative of apoptosis [16].

Physical exercise has been suggested as one of the noninvasive treatments for the prevention or treatment of various brain diseases, and treadmill running reduces the expression of genes related to apoptosis $[17,18]$. Regular exercise relieved symptoms in Parkinson disease mice such as decreased coordination, activated MAPK cascade, and proinflammatory cytokine production [19]. In this current research, we studied the effect of treadmill running on spatial learning memory in $\mathrm{AD}$-evoked rats in relation to the $\mathrm{NF}-\kappa \mathrm{B} / \mathrm{MAPK}$ signaling pathway. We also evaluated the effect of treadmill running on proinflammatory cytokine production and apoptosis. For this study, Morris water maze test was done for the detection of spatial learning memory. TUNEL staining, immunohistochemistry for cleaved caspase-3, and western blot for NF- $\kappa \mathrm{B}, \mathrm{I} \kappa \mathrm{B}, \mathrm{MAPK}, \mathrm{TNF}-\alpha$, IL-1 $\beta$ were performed.

\section{MATERIALS AND METHODS}

\section{Experimental Animals}

This experiment was deliberated by the Animal Care and Use Committee and acquired the approval number (KSNU-2020165). For the experimental procedure, 40 -week-old ( $400 \pm 20 \mathrm{~g})$ Sprague-Dawley male rats of were used. The animals were classified into control group, running group, AD-evoked group, and $\mathrm{AD}$-evoked with running group.

\section{AD Induction}

The experimental animals were anesthetized by intraperitoneal injection of Zoletil 50 (10 mg/kg; Virbac Laboratories, Carros, Franc), then the animals were put on a stereotaxic instrument. After drilling a hole in the skull with a dental drill, a 26-G needle was inserted into the lateral ventricle on each side of the brain. A $\beta$ (1-42) (Sigma Chemical Co., St. Louis, MO, USA) was diluted with saline to a concentration of $1 \mu \mathrm{g} / \mu \mathrm{L}$. As described below [20], $\mathrm{A} \beta$ was incubated for 72 hours at $37^{\circ} \mathrm{C}$ to 
obtain an aggregated form of $\mathrm{A} \beta$. The rats belong to $\mathrm{AD}$-evoked groups were injected with $0.5 \mu \mathrm{L}$ of $\mathrm{A} \beta$ with a Hamilton syringe, while the rats belong to control group and the rats belong to running group were injected with $0.5 \mu \mathrm{L}$ of saline.

\section{Exercise Protocol}

The rats belong to the running groups were allowed running on an electric treadmill machine (Columbus Instruments, Columbus, $\mathrm{OH}$, USA) for 30 minutes every day for 4 weeks starting from the 3 days after $A \beta$ injection (Fig. 1). The run kept the slope at $0^{\circ}$ and ran at a speed of $8 \mathrm{~m} / \mathrm{min}$ without stopping.

\section{Morris Water Maze Task}

Morris water maze task was done to detect the spatial learning memory of the experimental rats, as described below [16,21]. Water mixed with black paint was placed in a round tank (diameter, $140 \mathrm{~cm}$; height, $45 \mathrm{~cm}$ ). The rats dived from their initial starting point and learned for 1 minute to reach their submerged destination (diameter, $15 \mathrm{~cm}$; height, $35 \mathrm{~cm}$ ). The round tank was divided into 4 quadrants, and the rats had learning opportunity. Learning took place 21 days after the start of the treadmill exercise, and measurement took place 5 days after the training. After all the lessons were completed, the time and distance traveled to the destination were measured. The measurement equipment was a video equipment (Smart ver. 2.5, Panlab, Barcelona, Spain).

\section{Tissue Preparation}

Following Morris water maze task was completed, the rats were intraperitoneally injected with Zoletil $50(10 \mathrm{mg} / \mathrm{kg}$; Virbac Laboratories). Through the heart, $50 \mathrm{mM}$ phosphate-buffered saline was injected and followed by infusion of $50 \mathrm{mM}$ phosphate buffer containing $4 \%$ paraformaldehyde. After filling the $50-\mathrm{mL}$ tube with $4 \%$ paraformaldehyde, the extracted brains were immersed and left for a day for fixation.

\section{TUNEL Assay}

In order to find DNA fragmentation, TUNEL staining was done utilizing with the In Situ Cell Death Detection Kit (Roche, Mannheim, Germany), as explained below $[13,16]$. The sections were treated with ethanol-acetic acid (2:1), proteinase $\mathrm{K}$ (100 mg/mL), 3\% $\mathrm{H}_{2} \mathrm{O}_{2}, 0.5 \%$ Triton X-100, and TUNEL reaction mixture. After treating the sections with Converter-POD using $0.03 \%$ diaminobenzidine, Nissl staining was done for counterstaining, then placed on gelatin-coated slides.

\section{Immunohistochemistry}

Immunohistochemistry was done to find the cleaved caspase-3 in the hippocampus, as described below $[13,16]$. Tissues were blocked using horse serum for 1 hour, washed 3 times for 5 minutes, and incubated with rabbit anticleaved casepase-3 antibody (1:1,000; Cell Signaling Technology, Inc., Danvers, MS, USA) overnight. After one day, the tissues were reacted with the secondary antibody (1:200; Vector Laboratories, Burlingame, CA, USA) for 1 hour. The sections were treated with avidin-biotin-peroxidase complex (Vector Laboratories) for 1 hour and then incubated with a solution composing of $0.03 \% 3,3^{\prime}$ diaminobenzidine and $0.03 \%$ hydrogen peroxide for 5 minutes.

\section{Western Blot Analysis}

Western blot analysis was done, as explained below [16,22]. The primary antibodies were treated during 24 hours for TNF- $\alpha$ (1:1,000; Santa Cruz Biotechnology, Santa Cruz, CA, USA), IL$1 \beta$ (1:1,000; Santa Cruz Biotechnology), NF-кB (1:1,000; Abcam, Cambridge, UK), I $\kappa B a(1: 1,000$; Santa Cruz Biotechnolo-

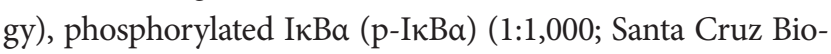
technology), extracellular signal-regulated kinase (ERK) (1:1,000; Cell Signaling Technology), phosphorylated ERK

MWM: Morris water maze

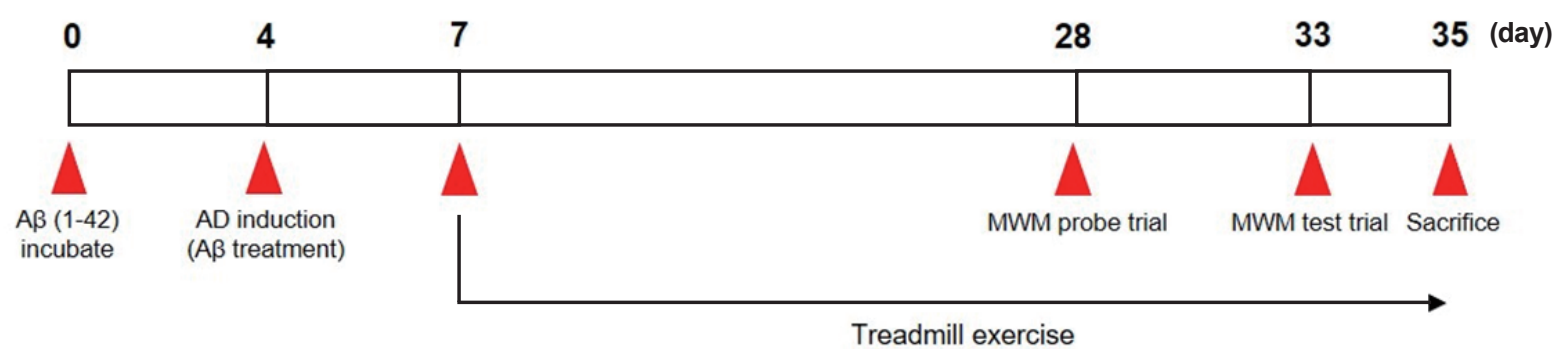

Fig. 1. Experimental schedule. AD, Alzheimer disease. 
(1:1,000; Cell Signaling Technology), c-Jun N-terminal kinases (JNK) (1:1,000; Cell Signaling Technology), phosphorylated JNK (1:1,000; Cell Signaling Technology), p38 (1:1,000; Cell Signaling Technology), and phosphorylated p38 (1:1,000; Cell Signaling Technology). The secondary antibodies were applied to the membrane, and then the bands were calculated by enhanced chemiluminescent kit.

\section{Data Analysis}

TUNEL-positive and cleaved caspase-3-positive cell number in the dentate gyrus of hippocampus were calculated by the optical microscope (Olympus, Tokyo, Japan). Western blot results were quantified by setting the control group as 1.00 . For statistical processing, IBM SPSS Statistics ver. 25.0 (IBM Co., Armonk, NY, USA) was used and the results were compared by 1-way analysis of variance followed by Duncan posttest. All data were presented as the mean \pm standard error of the mean, and statistically significance was determined at $\mathrm{P}<0.05$.

\section{RESULTS}

\section{Spatial Learning Memory in Morris Water Maze Test}

Data from the Morris water maze task were exhibited in Fig. 2. Induction of $\mathrm{AD}$ reduced spatial learning memory $(\mathrm{P}<0.05)$, and treadmill running ameliorated impairments of spatial learning memory in $\mathrm{AD}$-evoked rats $(\mathrm{P}<0.05)$.

\section{TNF- $\alpha$ and IL-1 $\beta$ Expression in Hippocampus}

Data from the western blotting of TNF- $\alpha$ and IL- $1 \beta$ were exhibited in Fig. 3. Induction of AD increased TNF- $\alpha$ and IL- $1 \beta$ expression $(\mathrm{P}<0.05)$, and treadmill running inhibited TNF- $\alpha$ and $\mathrm{IL}-1 \beta$ expression in $\mathrm{AD}$-evoked rats $(\mathrm{P}<0.05)$.

\section{NF-kB and I $\mathrm{kB}$ Expression in Hippocampus}

Data from the western blotting of NF- $\mathrm{KB}$ and I $\mathrm{kB}$ expression were exhibited in Fig. 4. Induction of $A D$ increased NF- $\kappa B$ expression and enhanced IкB phosphorylation $(\mathrm{P}<0.05)$. Treadmill running inhibited NF- $\kappa \mathrm{B}$ expression and suppressed IкBa phosphorylation in $\mathrm{AD}$-evoked rats $(\mathrm{P}<0.05)$.

\section{MAPK Cascade Expression in Hippocampus}

Data from the western blotting of MAPK cascade expression were exhibited in Fig. 5. Induction of $\mathrm{AD}$ increased phosphorylation of ERK, JNK, and $\mathrm{p} 38$ of the MAPK cascade $(\mathrm{P}<0.05)$, and treadmill running inhibited phosphorylation of ERK, JNK, and $\mathrm{p} 38$ in $\mathrm{AD}$-evoked rats $(\mathrm{P}<0.05)$
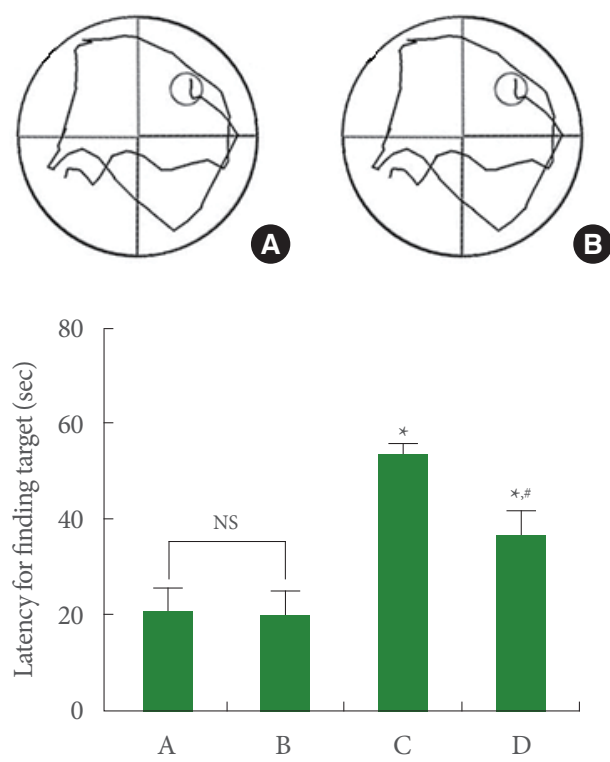
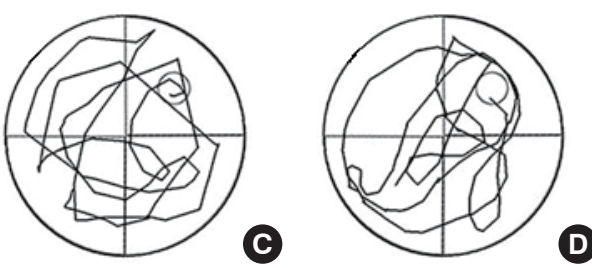

(D)

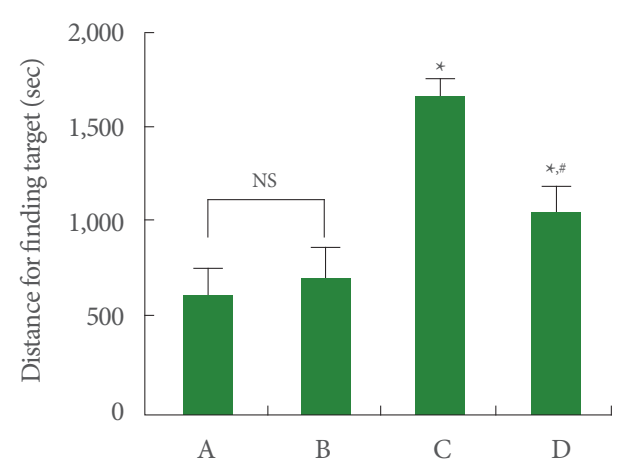

Fig. 2. Spatial learning memory. Upper panel: representative swimming path. Lower left panel: latency for finding target. Lower right panel: distance for finding target. A, control group; B, running group; C, Alzheimer disease (AD)-evoked group; D, AD-evoked and running group. ${ }^{*} \mathrm{P}<0.05$ compared to the control group. ${ }^{*} \mathrm{P}<0.05$ compared to the $\mathrm{AD}$-evoked group. NS, nonsignificant. 


\section{Apoptosis in Hippocampus}

Data from the apoptosis were exhibited in Fig. 6. Induction of $\mathrm{AD}$ increased TUNEL-positive and cleaved caspase-3-positive cell number in the dentate gyrus of hippocampus $(\mathrm{P}<0.05)$. Treadmill running suppressed TUNEL-positive and cleaved caspase-3-positive cell number in $\mathrm{AD}$-evoked rats $(\mathrm{P}<0.05)$.
Induction of $\mathrm{AD}$ increased Bax expression and suppressed Bcl2 expression, consequently increasing the $\mathrm{Bax}$ versus $\mathrm{Bcl}-2$ ratio $(\mathrm{P}<0.05)$. Treadmill running inhibited Bax expression and increased Bcl-2 expression, consequently decreasing the Bax versus $\mathrm{Bcl}-2$ ratio in $\mathrm{AD}$-evoked rats $(\mathrm{P}<0.05)$.
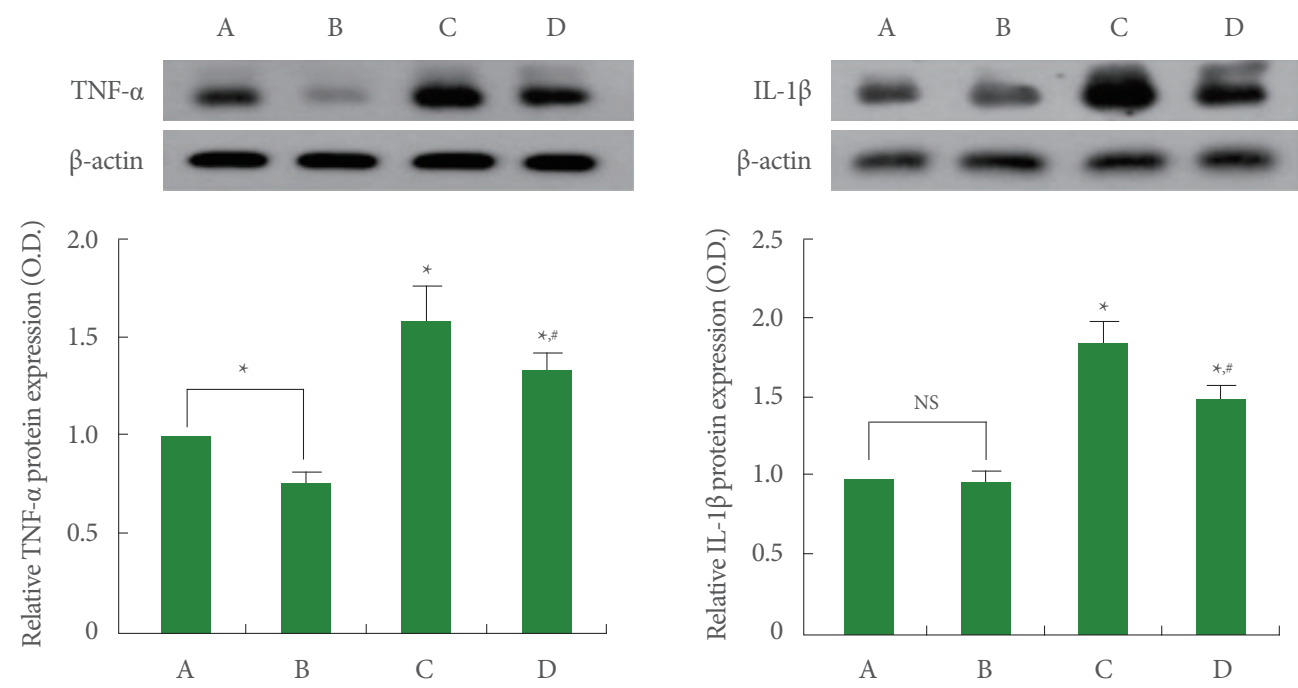

Fig. 3. Tumor necrosis factor-alpha (TNF- $\alpha$ ) and interleukin-1 beta (IL-1 $\beta$ ) expression in the hippocampus. Left upper panel: representative expression of TNF- $\alpha$. Left lower panel: relative expression of TNF- $\alpha$. Right upper panel: representative expression of IL-1 $\beta$. Right lower panel: relative expression of IL-1 $\beta$. A, control group; B, running group; C, Alzheimer disease (AD)-evoked group; D, ADevoked and running group. ${ }^{*} \mathrm{P}<0.05$ compared to the control group. ${ }^{*} \mathrm{P}<0.05$ compared to the $\mathrm{AD}$-evoked group. NS, nonsignificant.
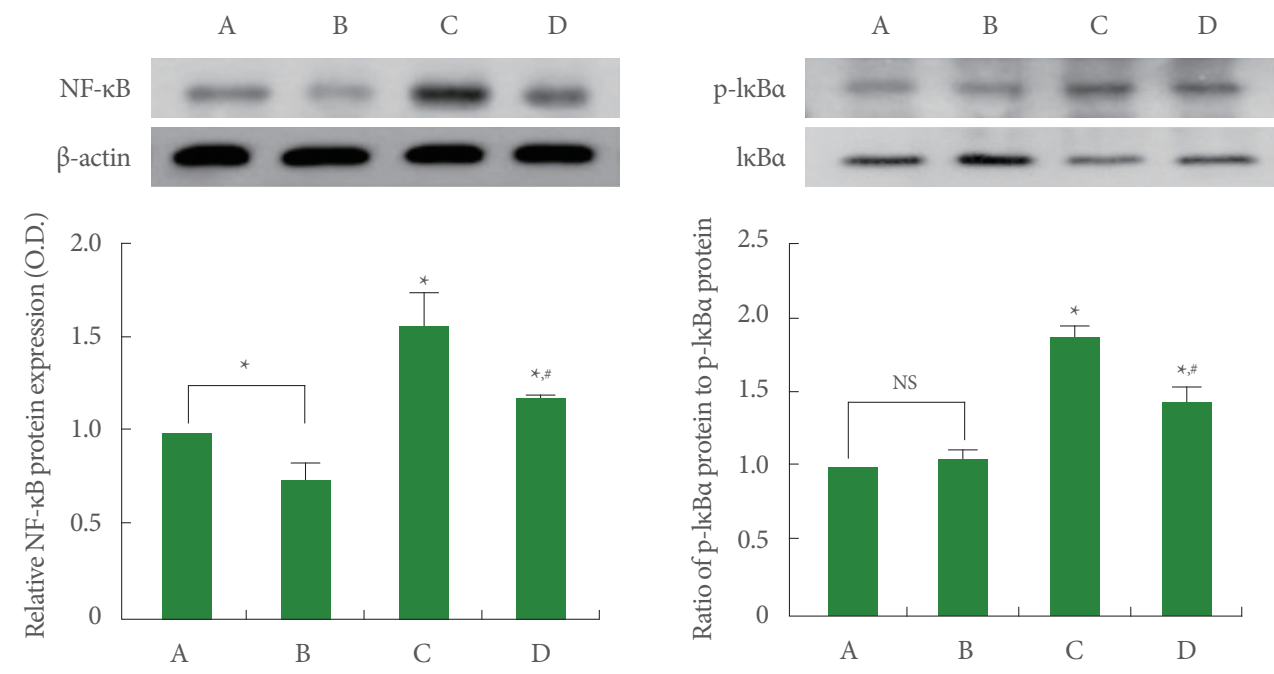

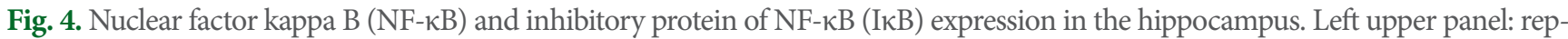

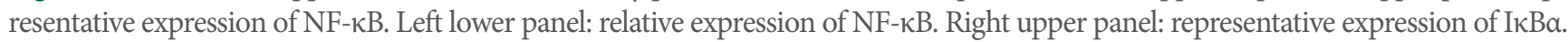
Right lower panel: relative expression of IкB $\alpha$. A, control group; B, running group; C, Alzheimer disease (AD)-evoked group; D, ADevoked and running group. ${ }^{*} \mathrm{P}<0.05$ compared to the control group. ${ }^{*} \mathrm{P}<0.05$ compared to the $\mathrm{AD}$-evoked group. $\mathrm{NS}$, nonsignificant. 

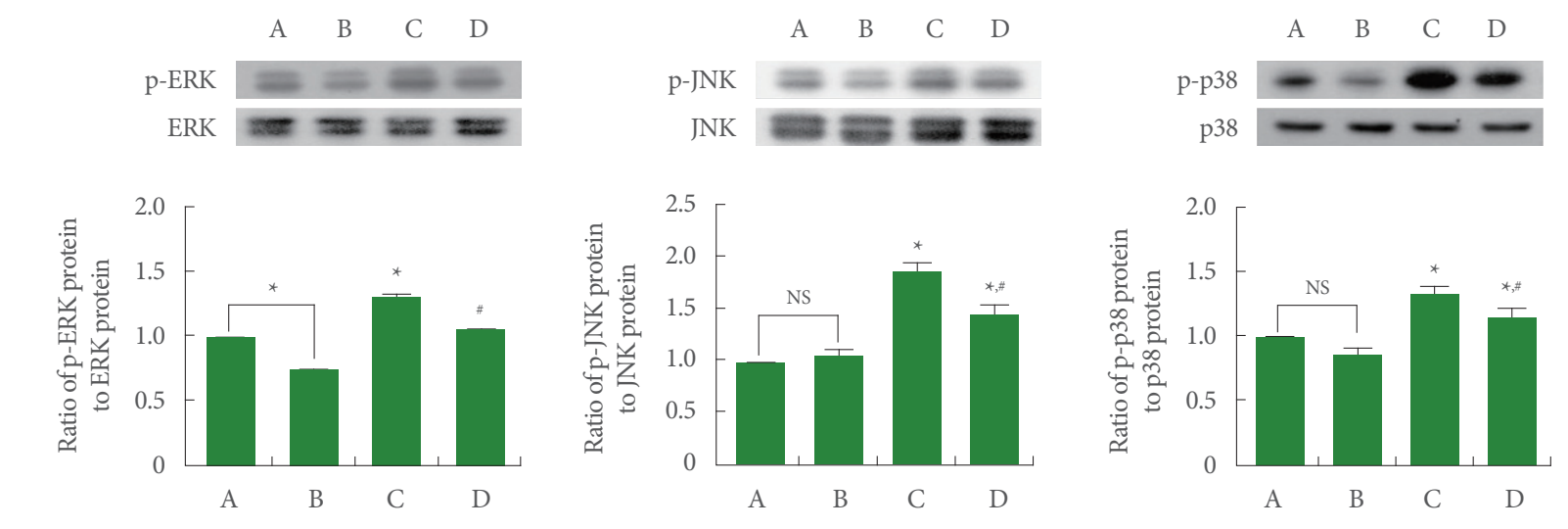

Fig. 5. Mitogen-activated protein kinase (MAPK) expression in the hippocampus. Left upper panel: representative expression of expression of extracellular signal-regulated kinase (ERK). Left lower panel: relative expression of ERK. Middle upper panel: representative expression of c-Jun N-terminal kinase (JNK). Middle lower panel: relative expression of JNK. Right upper panel: representative expression of p-38. Right lower panel: relative expression of p-38. A, control group; B, running group; C, Alzheimer disease (AD)evoked group; D, AD-evoked and running group. ${ }^{*} \mathrm{P}<0.05$ compared to the control group. ${ }^{*} \mathrm{P}<0.05$ compared to the $\mathrm{AD}$-evoked group. NS, nonsignificant.

\section{DISCUSSION}

The method of administering $A \beta$ to experimental animals is a representative method of inducing $A D$. Accumulation of $A \beta$ in the brain exerts devastating effects on the immune system [23]. Cells of the immune system release cytokines and chemokines that can influence the $\beta$-amyloid producing and/or aggregation [24]. Increased cytokine production is closely associated with decreased cognitive function [25]. Voluntary wheel running following brain inflammation inhibited proinflammatory cytokine production and apoptosis, then improved spatial learning memory [13]. Performing treadmill running improved spatial learning memory, short-term memory, and recognition memory [26-28]. In the current study, induction of $\mathrm{AD}$ was found to worsen the spatial learning memory in the Morris water maze task, whereas treadmill running improved $\mathrm{AD}$-induced spatial learning memory.

The NF-kB/MAPK signaling pathway regulates inflammation through transcription of TNF- $\alpha$ and IL-1 $\beta$ [29]. The deposition of $A \beta$ activates the MAPK cascade, including JNK, ERK, and $\mathrm{p} 38$, and then produces proinflammatory cytokines that are translocated to the nucleus in the NF- $\mathrm{kB}$ complex [30]. Tau hyperphosphorylation, $A \beta$ toxicity, autophagy deregulation, and apoptosis are caused by activation of signaling pathways in the NF- $\mathrm{\kappa B}$ and MAPK cascade [31]. Voluntary wheel running inactivated the signaling pathway of the NF- $\kappa B$ [13]. In the current study, induction of $\mathrm{AD}$ enhanced NF- $\mathrm{kB}$ expression and increased I $\mathrm{B} B a$ phosphorylation. Induction of $\mathrm{AD}$ also increased phosphorylation of JNK, ERK, and p38. The results mean that $\mathrm{AD}$ induction activated MAPK signaling pathway. Treadmill running suppressed MAPK expression and decreased IkB $a$ phosphorylation. Treadmill running also suppressed phosphorylation of JNK, ERK, and p38. The results mean that treadmill running inactivated NF-KB/MAPK signaling pathway.

TNF- $\alpha$ and IL- $1 \beta$ production was increased during acute liver injury, and these proinflammatory cytokines exacerbated symptoms of acute liver injury [29]. Production of TNF- $\alpha$ and IL-6 in the hippocampus was suppressed by voluntary wheel running following brain inflammation [13]. In the current study, $\mathrm{AD}$ induction enhanced the production of TNF- $\alpha$ and IL-1 $\beta$ in the brain of AD-evoked rats. Treadmill running suppressed TNF- $\alpha$ and IL- $1 \beta$ production in $\mathrm{AD}$-evoked rats.

In animal $\mathrm{AD}$ model, elevated $\mathrm{A} \beta$ caused apoptosis after injury or disease, and inhibition of caspases protected from apoptosis [32]. Apoptotic neuronal cell death and impaired spatial learning memory due to $A \beta$ deposition in the hippocampus were observed in $\mathrm{AD}$ transgenic mice [33]. During acute liver injury, Bax expression was enhanced and Bcl-2 expression was suppressed, leading to increased apoptosis [29]. Voluntary wheel running inhibited the number of TUNEL-positive and caspase-3-positive cells in the hippocampus during brain inflammation [13]. Voluntary wheel running also suppressed Bax expression and increased Bcl-2 expression in the hippocampus 

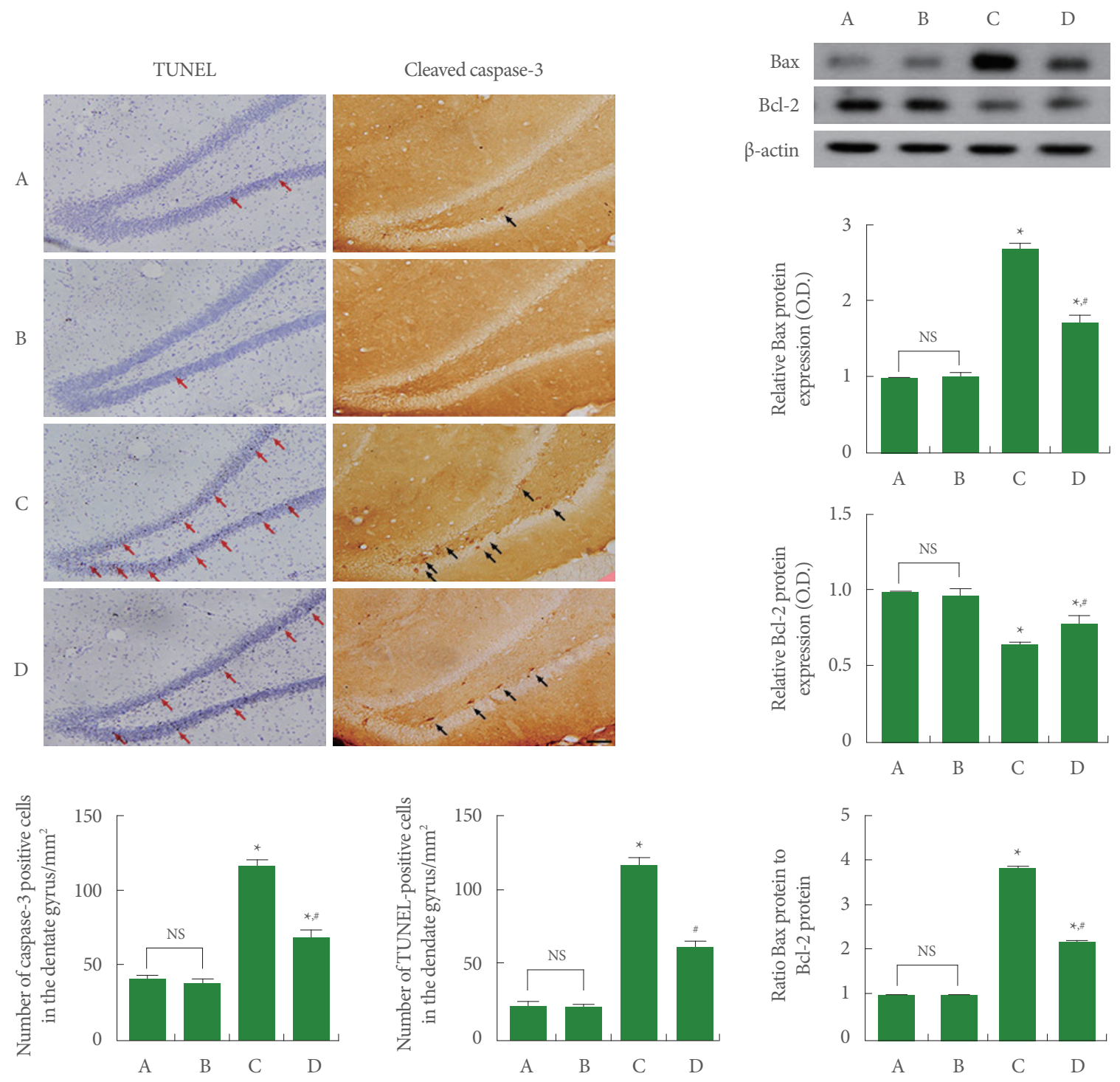

Fig. 6. Apoptosis in the hippocampus. Left upper panel: photomicrographs of terminal deoxynucleotidyl transferase dUTP nick end labeling (TUNEL)-positive cells (red arrows) and cleaved caspase-3-positive cells (black arrows) in the dentate gyrus of hippocampus. The scale bar represents $100 \mu \mathrm{m}$. Left lower panel: number of TUNEL-positive cells and cleaved caspase-3-positive cells. Right upper panel: representative expression of Bcl-2-associated X protein (Bax) and B-cell lymphoma-2 (Bcl-2) in the hippocampus. Right lower panel: expression of Bax, Bcl-2, and ratio of Bax to Bcl-2. A, control group; B, treadmill running group; C, Alzheimer disease (AD)evoked group; $\mathrm{D}, \mathrm{AD}$-evoked and running group. ${ }^{\star} \mathrm{P}<0.05$ compared to the control group. ${ }^{*} \mathrm{P}<0.05$ compared to the $\mathrm{AD}$-evoked group. NS, nonsignificant.

after brain inflammation [13]. In socially isolated old rats, TUNEL-positive cell number and Bax expression were inhibited, and Bcl-2 expression was suppressed, indicating an accelerated apoptosis [16]. Meanwhile, swimming reduced TUNEL-positive cell number and Bax expression, and increased Bcl-2 expression, resulting in suppressed apoptosis [16]. In the current study, the number of TUNEL-positive and cleaved caspase- 3-positive cells, the expression of Bax, and the ratio of Bax to $\mathrm{Bcl}-2$ were enhanced, while the expression of $\mathrm{Bcl}-2$ was suppressed in AD-evoked rats. TUNEL-positive and cleaved caspase-3-positive cell number, Bax expression, and Bax to Bcl-2 ratio were suppressed and $\mathrm{Bcl}-2$ expression was increased by treadmill running in $\mathrm{AD}$-evoked rats.

Current results show that treadmill running has an increas- 
ing impact on spatial learning memory through suppressing proinflammatory cytokine production and apoptosis via inactivation of the NF-kB/MAPK signaling pathway. Treadmill exercise can be considered as an effective intervention for alleviating $\mathrm{AD}$ symptoms.

\section{AUTHOR CONTRIBUTION STATEMENT}

- Conceptualization: $S H K$

- Data curation: $Y J K, J Y K$

- Formal analysis: $Y J K, J Y K$

- Funding acquisition: YJS

- Methodology: YJK, JYK

- Project administration: YJS

- Visualization: YJS

- Writing-original draft: $S H K$

- Writing-review \& editing: $S H K$

\section{ORCID}

Sang-Hoon Kim https://orcid.org/0000-0002-8867-8822

Young Jun Ko https://orcid.org/0000-0001-5469-7235

Jee-Youn Kim https://orcid.org/0000-0002-4408-5777

Young-Je Sim https://orcid.org/0000-0002-9574-3135

\section{REFERENCES}

1. Kim B, Choi Y, Kim HS, Im HI. Methyl-CpG binding protein 2 in Alzheimer dementia. Int Neurourol J 2019;23:72-81.

2. Agnihotri A, Aruoma OI. Alzheimer's disease and Parkinson's disease: a nutritional toxicology perspective of the impact of oxidative stress, mitochondrial dysfunction, nutrigenomics and environmental chemicals. J Am Coll Nutr 2020;39:16-27.

3. Wyss-Coray T, Rogers J. Inflammation in Alzheimer disease-a brief review of the basic science and clinical literature. Cold Spring Harb Perspect Med 2012;2:a006346.

4. Kinney JW, Bemiller SM, Murtishaw AS, Leisgang AM, Salazar AM, Lamb BT. Inflammation as a central mechanism in Alzheimer's disease. Alzheimers Dement (N Y) 2018;4:575-90.

5. An J, Park SH, Ko IG, Jin JJ, Hwang L, Ji ES, et al. Polydeoxyribonucleotide ameliorates lipopolysaccharide-induced lung injury by inhibiting apoptotic cell death in rats. Int J Mol Sci 2017;18:1847.

6. Song SH, Jee YS, Ko IG, Lee SW, Sim YJ, Kim DY, et al. Treadmill exercise and wheel exercise improve motor function by suppressing apoptotic neuronal cell death in brain inflammation rats. J Ex- erc Rehabil 2018;14:911-19.

7. Meraz-Ríos MA, Toral-Rios D, Franco-Bocanegra D, VilledaHernández J, Campos-Peña V. Inflammatory process in Alzheimer's disease. Front Integr Neurosci 2013;7:59.

8. Alasmari F, Ashby CR Jr, Hall FS, Sari Y, Tiwari AK. Modulation of the ATP-binding cassette b1 transporter by neuro-inflammatory cytokines: role in the pathogenesis of Alzheimer's disease. Front Pharmacol 2018;9:658.

9. Rogers J, Mastroeni D, Leonard B, Joyce J, Grover A. Neuroinflammation in Alzheimer's disease and Parkinson's disease: are microglia pathogenic in either disorder? Int Rev Neurobiol 2007;82:23546.

10. Tufekci KU, Meuwissen R, Genc S, Genc K. Inflammation in Parkinson's disease. Adv Protein Chem Struct Biol 2012;88:69-132.

11. Combs CK, Johnson DE, Karlo JC, Cannady SB, Landreth GE. Inflammatory mechanisms in Alzheimer's disease: inhibition of $\beta$-amyloid-stimulated proinflammatory responses and neurotoxicity by PPAR $\gamma$ agonists. J Neurosci 2000;20:558-67.

12. Yue J, López JM. Understanding MAPK signaling pathways in apoptosis. Int J Mol Sci 2020;21:2346.

13. Ko YJ, Ko IG. Voluntary wheel running improves spatial learning memory by suppressing inflammation and apoptosis via inactivation of nuclear factor kappa B in brain inflammation rats. Int Neurourol J 2020;24:96-103.

14. Ko IG. Therapeutic strategies against apoptosis and gliosis. Int Neurourol J 2020;24:65-6.

15. Zhang Z, Li X, Li D, Luo M, Li Y, Song L, et al. Asiaticoside ameliorates $\beta$-amyloid-induced learning and memory deficits in rats by inhibiting mitochondrial apoptosis and reducing inflammatory factors. Exp Ther Med 2017;13:413-20.

16. Park SS, Park HS, Kim TW, Lee SJ. Effects of swimming exercise on social isolation-induced memory impairment and apoptosis in old rats. J Exerc Rehabil 2020;16:234-41.

17. Kim SE, Ko IG, Kim BK, Shin MS, Cho S, Kim CJ, et al. Treadmill exercise prevents aging-induced failure of memory through an increase in neurogenesis and suppression of apoptosis in rat hippocampus. Exp Gerontol 2010;45:357-65.

18. Park HS, Kim TW, Park SS, Lee SJ. Swimming exercise ameliorates mood disorder and memory impairment by enhancing neurogenesis, serotonin expression, and inhibiting apoptosis in social isolation rats during adolescence. J Exerc Rehabil 2020;16:132-40.

19. Bohush A, Niewiadomska G, Filipek A. Role of mitogen activated protein kinase signaling in Parkinson's disease. Int J Mol Sci 2018;19:2973.

20. Kantar Gok D, Hidisoglu E, Ocak GA, Er H, Acun AD, Yargıcoglu P. 
Protective role of rosmarinic acid on amyloid beta 42-induced echoic memory decline: Implication of oxidative stress and cholinergic impairment. Neurochem Int 2018;118:1-13.

21. Ko YJ, Kim BK, Ji ES. Treadmill exercise in obese maternal rats during pregnancy improves spatial memory through activation of phosphatidylinositol 3-kinase pathway in the hippocampus of rat pups. J Exerc Rehabil 2020;16:483-8.

22. Yoo SZ, No MH, Heo JW, Chang E, Park DH, Kang JH, et al. Effects of a single bout of exercise on mitochondria-mediated apoptotic signaling in rat cardiac and skeletal muscles. J Exerc Rehabil 2019;15:512-17.

23. Cioanca O, Hritcu L, Mihasan M, Trifan A, Hancianu M. Inhalation of coriander volatile oil increased anxiolytic-antidepressantlike behaviors and decreased oxidative status in beta-amyloid (142) rat model of Alzheimer's disease. Physiol Behav 2014;131:6874.

24. Domingues $C$, da Cruz E Silva OAB, Henriques AG. Impact of cytokines and chemokines on Alzheimer's disease neuropathological hallmarks. Curr Alzheimer Res 2017;14:870-82.

25. Su F, Bai F, Zhang Z. Inflammatory cytokines and Alzheimer's disease: a review from the perspective of genetic polymorphisms. Neurosci Bull 2016;32:469-80.

26. Kim TW, Park SS, Shin MS, Park HS, Baek SS. Treadmill exercise ameliorates social isolation-induced memory impairment by enhancing silent information regulator-1 expression in rats. J Exerc Rehabil 2020;16:227-33.
27. Kim TW, Baek KW, Yu HS, Ko IG, Hwang L, Park JJ. High-intensity exercise improves cognitive function and hippocampal brainderived neurotrophic factor expression in obese mice maintained on high-fat diet. J Exerc Rehabil 2020;16:124-31.

28. Farzi MA, Sadigh-Eteghad S, Ebrahimi K, Talebi M. Exercise improves recognition memory and acetylcholinesterase activity in the beta amyloid-induced rat model of Alzheimer's disease. Ann Neurosci 2019;25:121-25.

29. Lee S, Won KY, Joo S. Protective effect of polydeoxyribonucleotide against CCl4-induced acute liver injury in mice. Int Neurourol J 2020;24:88-95.

30. Cai X, Chen Y, Xie X, Yao D, Ding C, Chen M. Astaxanthin prevents against lipopolysaccharide-induced acute lung injury and sepsis via inhibiting activation of MAPK/NF-kB. Am J Transl Res 2019;11:1884-94.

31. Kheiri G, Dolatshahi M, Rahmani F, Rezaei N. Role of p38/MAPKs in Alzheimer's disease: implications for amyloid beta toxicity targeted therapy. Rev Neurosci 2018;30:9-30.

32. Calissano P, Matrone C, Amadoro G. Apoptosis and in vitro Alzheimer disease neuronal models. Commun Integr Biol 2009;2: 163-9.

33. Zhong L, Liu H, Zhang W, Liu X, Jiang B, Fei H, et al. Ellagic acid ameliorates learning and memory impairment in APP/PS1 transgenic mice via inhibition of $\beta$-amyloid production and tau hyperphosphorylation. Exp Ther Med 2018;16:4951-8. 